\title{
28 Research Square \\ Measuring and tailoring Li-ion interfacial transport in hybrid solid electrolytes
}

Ming Liu

Delft University of Technology

Ernst van Eck

Radboud University Nijmegen

Swapna Ganapathy

Delft University of Technollogy

Marnix Wagemaker ( $\nabla$ m.wagemaker@tudelft.nl )

Delft University of Technology https://orcid.org/0000-0003-3851-1044

\section{Article}

Keywords: solid state batteries, hybrid solid electrolytes, spectroscopy

Posted Date: October 5th, 2021

DOl: https://doi.org/10.21203/rs.3.rs-953468/v1

License: (c) (1) This work is licensed under a Creative Commons Attribution 4.0 International License.

Read Full License

Version of Record: A version of this preprint was published at Nature Nanotechnology on July 21 st, 2022. See the published version at https://doi.org/10.1038/s41565-022-01162-9. 


\section{Abstract}

Development of commercial solid-state batteries so far been hindered by the individual limitations of inorganic and organic solid-electrolytes, motivating hybrid concepts. However, room-temperature performance of hybrid-solid electrolytes is still insufficient in terms of ion conductivity, where especially the role and impact of the inorganic and organic interphases is largely unexplored. A key challenge is to assess the Li-ion transport over the interfaces directly and relate this to the surface chemistry. Here the lithium-ion conductivity in hybrid-solid electrolytes, the interface structure and $\mathrm{Li}^{+}$interface transport was investigated by state-of-art solid-state nuclear magnetic resonance methodologies. In a hybrid-solid Polyethylene oxide polymer - inorganic electrolyte, two representative types of ionic liquids, having a different miscibility with the polymer, were used as a benchmark to tailor the local environment at the interface between the inorganic and organic solid electrolytes species. The poor miscibility ionic liquid wets the polymer-inorganic interface and raises the local polarizability, thereby lowering the diffusional barrier, which activates the high conductivity of the inorganic solid-electrolyte, resulting in and overall room temperature conductivity of $0.25 \mathrm{mS} / \mathrm{cm}$. A very high critical current density of $0.25 \mathrm{~mA} / \mathrm{cm}^{2}$ versus a Li-metal anode is achieved, demonstrating improved stability, and a $\mathrm{LiFePO}_{4}$ - Li-metal full solid-state cell can be cycled at room temperature at an Coulombic efficiency of $99.9 \%$. The local interface environment between the solid electrolyte phases in hybrid solid electrolytes, is thus demonstrated to be the bottleneck and tailoring the interface properties appears a viable route towards the design of highly conducting hybrid-solid electrolyte concepts.

\section{Introduction}

Solid-state batteries are recognized as a key candidate for next generation batteries because of their potential to improve both energy density and safety. ${ }^{1,2}$ However, the progress in solid-state battery development is hindered by the many criteria that solid-electrolytes need to satisfy to become commercially viable. These include high ionic conductivity, flexibility, (electro)chemical stability, compatibility with both cathode and anode materials and processability which are often hard to fulfill with an individual organic or inorganic solid electrolyte material. ${ }^{3-7}$ This has led to the investigation of hybrid electrolyte concepts, that typically combine an organic and an inorganic phase, in the quest find a solid-electrolyte that satisfies most if not all of the required criteria. ${ }^{8-10}$ An intensively investigated hybrid solid electrolyte (HSE) comprises of inorganic filler particles embedded in a conductive organic polymer matrix. The use of polyethylene oxide (PEO) as the organic polymer component together with a Li containing salt is especially attractive due to a number of unique advantages, i.e.: relative stability towards lithium metal, excellent contact/adhesion with electrodes, superior mechanical properties, and good flexibility that make it also easy to produce as thin films on a large scale. ${ }^{11-15}$ Properties of the inorganic component within the organic matrix play a crucial role in determining the final properties of the HSE. These include particle size $(<10 \mu \mathrm{m})$, relative amount $(<10 \%)$ and morphology. This has been well elucidated for the most common inorganic fillers which include $\mathrm{SiO}_{2}, \mathrm{Al}_{2} \mathrm{O}_{3}, \mathrm{TiO}_{2}$, zeolites, piezoelectric ceramics and $\mathrm{Li}^{+}$ceramic conductors. ${ }^{12,16-18}$ Typically, these inorganic fillers are added to 
lower the glass transition temperature $\left(\mathrm{T}_{\mathrm{g}}\right)$ of PEO, and enhance the polymer chain segmental mobility, resulting higher ionic conductivity. ${ }^{12,16-18}$

More recently, HSEs with inorganic ionic conductors as additive have been investigated aiming to provide additional and highly conductive pathways for $\mathrm{Li}^{+}$transport, a promising route to improve the $\mathrm{Li}$-ion conductivity of the HSE. ${ }^{16,18-22}$ However, despite the high ionic conductivity of these inorganic fillers, the room temperature Li-ion conductivity of the HSE remains far from what is demanded for all-solid-statebatteries $(\sim 1 \mathrm{mS} / \mathrm{cm})$. To gain insight in the possibility to improve the conductivity of HSEs one of the key challenges is to determine the exact Li-ion diffusion pathway through the heterogeneous hybrid solid electrolyte and the role of the interface structure between the organic and inorganic components.

This question remains difficult to answer due to the inherent challenge of directly monitoring $\mathrm{Li}^{+}$transport in HSEs, especially at the sub-nano scale of the interfaces. Several approaches have been reported which explore the correlation between interface environment and $\mathrm{Li}^{+}$movement in HSEs. ${ }^{4,16,23-26}$ Threedimensional (3D) structural reconstruction of HSEs obtained from synchrotron experiments and physicsbased modeling indicate that the inorganic particles are highly aggregated in the electrolyte, which would affect the internal $\mathrm{Li}^{+}$transport between different phases. ${ }^{4,23}$ Four-point electrochemical impedance measurements and surface-sensitive X-ray photoelectron spectroscopy revealed decomposition reactions between the organic and inorganic phases, which may significantly affect the $\mathrm{Li}^{+}$transport. ${ }^{24,25}$ Recently, combining selective isotope labeling with high-resolution solid-state nuclear magnetic resonance (NMR), $\mathrm{Li}^{+}$diffusion pathways were tracked within a $\mathrm{Li}_{7} \mathrm{La}_{3} \mathrm{Zr}_{2} \mathrm{O}_{12}$ (LLZO)-PEO HSE. ${ }^{16}$ This study showed that with an increase in the fraction of ceramic $\mathrm{Li}_{7} \mathrm{La}_{3} \mathrm{Zr}_{2} \mathrm{O}_{12}$ (LLZO) phase in the LLZO-PEO composite, $\mathrm{Li}^{+}$ mobility decreases, the $\mathrm{Li}^{+}$diffusion pathways change from polymer to ceramic routes, and that the active ion concentration increases. ${ }^{16,26}$ While these studies provide insight into $\mathrm{Li}^{+}$transport in HSEs, it is also evident that it remains a challenge to directly access the interfacial structure, correlate this to the $\mathrm{Li}^{+}$ transport across the interphase and use this to develop strategies to improve the conductivity of hybrid solid electrolytes. ${ }^{10}$

In an effort to gain deeper insight into the $\mathrm{Li}^{+}$transport in HSEs, specifically in conjunction with the inorganic-organic interface structure, we employed an experimental approach using electrochemical impedance spectroscopy and multinuclear solid-state NMR. This allows us to measure the bulk conductivity as well as directly access the interface structure and interfacial $\mathrm{Li}^{+}$diffusion in a HSE comprising of a LiTFSI (lithium bistrifluoromethanesulfonimidate)-PEO organic and argyrodite $\mathrm{Li}_{6} \mathrm{PS}_{5} \mathrm{Cl}$ inorganic component. Unsurprisingly we find that the ionic conductivity of the HSE is impeded by the chemical structure of the decomposition layer between the organic and inorganic phases, which remains a bottleneck for $\mathrm{Li}^{+}$diffusion. To overcome this, a strategy is devised where the interphase structure is perturbed by the addition of an ionic liquid to the HSE, which is poorly miscible with PEO. The addition of the piperdinium-based ionic liquid 'activates' the interface, enabling $\mathrm{Li}^{+}$diffusion between the organic and inorganic phases which is visualized with two-dimensional (2D) ${ }^{7} \mathrm{Li}$ exchange NMR. We propose that the 
ionic liquid, due to its poor miscibility with PEO is pushed to the interface where it alters the interface structure enhamcing $\mathrm{Li}^{+}$transport between the two phases and effectively contributing towards the ionic conductivity of the HSE. Solid-state NMR is proved as powerful methodology in resolving the sub-nano domain of interfacial environment, impossible by other traditional characterization techniques. Hereby the bottleneck of $\mathrm{Li}^{+}$transport in HSEs is revealed, and new design strategies proposed, supporting design of future solid state electrolytes.

\section{Interface structure and Li-ion diffusion in hybrid LiTFSI-PEO-LPSC solid electrolyte}

With the aim to improve the overall $\mathrm{Li}^{+}$conductivity of a LiTFSI-PEO polymer electrolyte, highly conductive micron sized argyrodite $\mathrm{Li}_{6} \mathrm{PS}_{5} \mathrm{Cl}$ (SEM image of $\mathrm{Li}_{6} \mathrm{PS}_{5} \mathrm{Cl}$ in Figure $\mathrm{S} 1$ ) is mixed in the LiTFSI-PEO with a weight fraction of $10 \%$, as detailed in the experimental section and shown in the SEM image. In order for $\mathrm{Li}_{6} \mathrm{PS}_{5} \mathrm{Cl}$ to contribute to the bulk conductivity of this hybrid solid electrolyte, facile Liion diffusion over the interfaces between the LiTFSI-PEO phase and the $\mathrm{Li}_{6} \mathrm{PS}_{5} \mathrm{Cl}$ particles is a prerequisite. The argyrodite $\mathrm{Li}_{6} \mathrm{PS}_{5} \mathrm{Cl}$ was selected as the inorganic filler in order to facilitate interfacial transport, as it possesses high ionic conductivity as well as high ductility, the latter enabling the formation of more soft interfaces that facilitate interfacial Li-ion diffusion. ${ }^{27}$ To study the $\mathrm{Li}^{+}$diffusion across the polymer electrolyte $-\mathrm{Li}_{6} \mathrm{PS}_{5} \mathrm{Cl}$ interface and to resolve the interface structure between the organic and inorganic phases, magic angle spinning (MAS) ${ }^{6,7} \mathrm{Li}$ solid-state NMR is employed. This allows us to discriminate between Li-ions in different chemical environments, in this case in the PEO and $\mathrm{Li}_{6} \mathrm{PS}_{5} \mathrm{Cl}$ phases. ${ }^{16,27}$ One-dimensional (1D) ${ }^{7} \mathrm{Li}$ MAS NMR spectra and two-dimensional (2D) ${ }^{7} \mathrm{Li}-{ }^{7} \mathrm{Li}$ and ${ }^{6} \mathrm{Li}-{ }^{6} \mathrm{Li}$ exchange spectra (2D-EXSY) of the hybrid LiTFSI-PEO- $\mathrm{Li}_{6} \mathrm{PS}_{5} \mathrm{Cl}$ electrolyte are shown in Figure 1ac. As seen in Figure 1a, the LiTFSI-PEO and $\mathrm{Li}_{6} \mathrm{PS}_{5} \mathrm{Cl}$ show two clear resonances with ${ }^{7} \mathrm{Li}$ chemical shifts of -1.39 and 1.44 ppm, respectively. Based on the difference in ${ }^{6,7} \mathrm{Li}$ chemical shift of the LiTFSI-PEO and $\mathrm{Li}_{6} \mathrm{PS}_{5} \mathrm{Cl}$ phases, $2 \mathrm{D}$-EXSY experiments provide selective and non-invasive quantification of the spontaneous $\mathrm{Li}^{+}$diffusion over the solid-solid interphase between these phases. The detailed principle of the 2D-EXSY experiment can be found elsewhere and is additionally briefly set out in the experimental section. ${ }^{27,28} \mathrm{Li}^{+}$exchange between these two chemical environments would result in off-diagonal crosspeaks at the positions indicated with dotted boxes in Figure $1 \mathrm{~b}$ and $\mathrm{c}$. Increasing the mixing time, $T_{\text {mix }}$ therefore providing more time for the Li-ions to diffuse from one phase to the other, as well as increasing the temperature, is expected to increase the Li-ion exchange flux, and thus the intensity of the offdiagonal cross-peaks. ${ }^{27}$ In this case the absence of cross-peaks, even for the maximum $\mathrm{T}_{\text {mix }}$ and temperature ( $T_{\text {mix }}=2 \mathrm{~s}$ and $2.5 \mathrm{~s}, 328 \mathrm{~K}$ ) that can be achieved, indicates that the $\mathrm{Li}^{+}$exchange (flux) between $\mathrm{LiTFSI}$-PEO and $\mathrm{Li}_{6} \mathrm{PS}_{5} \mathrm{Cl}$ phases is very small, indicating very slow $\mathrm{Li}^{+}$diffusion across the interfaces within this HSE.

To discern the origin for the poor Li-ion diffusion across the interfaces between the organic and inorganic phases, $1 \mathrm{D}{ }^{6} \mathrm{Li}$ cross-polarization MAS (CPMAS) and 2D ${ }^{1} \mathrm{H}-{ }^{6} \mathrm{Li}$ heteronuclear correlation (HETCOR) experiments were carried out (Figure 1d, e) which allows to resolve the interface composition and 
structure. In these experiments, transfer of polarization occurs from protons $\left({ }^{1} \mathrm{H}\right)$, in this case abundantly present in the polymer, to any ${ }^{6} \mathrm{Li}$ environment in its near (few bonds range) vicinity. This takes place during a varying time interval referred to as the contact time, typically in the range of $200 \mu \mathrm{s}-10 \mathrm{~ms}$. With the direct ${ }^{6,7} \mathrm{Li}$ excitation, only two peaks are resolved as shown in Figure 1a for ${ }^{7} \mathrm{Li}$ (Figure $\mathbf{S} 2$ for ${ }^{6} \mathrm{Li}$ ). However, the ${ }^{6} \mathrm{Li}$ CPMAS spectrum resolves several additional resonances between $1 \mathrm{ppm}$ and -1.5 ppm (Figure 1d). In addition to the peak assigned to LiTFSI in PEO, peaks are assigned to polysulfides and phosphorus sulfide species, well in accordance with previous literature reported using XPS. ${ }^{24,25}$ This indicates that there are inorganic decomposition products accumulated the interface that could inhibit interfacial $\mathrm{Li}^{+}$transport. The $2 \mathrm{D}{ }^{1} \mathrm{H}-{ }^{6} \mathrm{Li}$ HETCOR experiment at a short contact time shows correlation between ${ }^{1} \mathrm{H}$ and ${ }^{6} \mathrm{Li}$ species either directly bonded to, or in very close proximity to, each other. As can be seen in Figure 1e, at a short contact time of $0.2 \mathrm{~ms}$ the different Li species observed are in contact with a single ${ }^{1} \mathrm{H}$ environment at a chemical shift of $\sim 1.6 \mathrm{ppm}$, which can be assigned to the alkyl $-\mathrm{CH}_{2}$ - group. This has also been identified as the main decomposition product of PEO chains when in contact with $\mathrm{Li}_{6} \mathrm{PS}_{5} \mathrm{Cl}$ from XPS studies reported elsewhere. ${ }^{24,25,29}$ This indicates that there are interfacial reactions between $\mathrm{Li}_{6} \mathrm{PS}_{5} \mathrm{Cl}$ and $\mathrm{PEO}$, resulting in an inert environment deficient in ethereal oxygen that is knownto mediate the $\mathrm{Li}^{+}$diffusion in PEO (Figure 1f). This poorly Li-ion conducting interface environment is held responsible for the absence of Li-ion exchange in Figure $\mathbf{1 b}$ and $\mathbf{1 c}$, indicating sluggish Li-ion diffusion between the two electrolyte phases. These findings can potentially explain the difficulties in activating inorganic particles in hybrid solid electrolyte (HSE), ${ }^{16}$ indicating that the interface needs to be improved to enhance the Li-ion interfacial diffusion.

\section{Electrochemical evaluation of the hybrid solid electrolyte upon introduction of ionic liquids}

Based on the findings detailed in the previous section, it is clear that an inert interphase is formed between LiTFSI-PEO and $\mathrm{Li}_{6} \mathrm{PS}_{5} \mathrm{Cl}$ which impedes charge transport in the HSE. Traditionally, ionic liquids (ILs) have been used to enhance the segmental motion of PEO chains and subsequently can affect the $\mathrm{Li}^{+}$mobility. ${ }^{9,30}$ These ILs do not form strong ionic bonds between their cation and anion moieties and hence possess low solvation energy and remain in a dissociated state. It has been shown in previous studies that imidazole-based ionic liquids are effective in improving the conductivity of PEO, because of their low viscosity and high miscibility in PEO. ${ }^{30}$

To determine whether an IL when added to the HSE has impact on the conductivity and interfacial charge diffusivity between the organic and inorganic phases, two ILs that differ significantly in their viscosity and miscibility with PEO were selected. The first is an imidazole-based IL 1-Ethyl-3-methylimidazolium bis(trifluoromethylsulfonyl)imide (denoted as EMIM TFSI) (Figure 2a) and the second is a piperidinium- 
based IL 1-Methyl-1-propylpiperidinium bis(trifluoromethylsulfonyl)imide (denoted as PP13 TFSI) (Figure 2b). These ILs each have a very different miscibility with $\mathrm{PEO}^{31}$ based on which the hypothesis is that the IL with a low miscibility with PEO i.e. PP13 TFSI will be pushed towards the interface with the inorganic $\mathrm{Li}_{6} \mathrm{PS}_{5} \mathrm{Cl}$ phase, aiming to improve the Li-ion diffusion at the interface, and thus improving the interfacial charge transport. In contrast, the highly miscible EMIM TFSI will be distributed homogenously in the HSE and not specifically influence Li-ion transport across the organic-inorganic interface. To test this hypothesis, a fixed amount of EMIM-TFSI and PP13-TFSI in a 0.25:1 molar ratio IL:LiTFSI are added to the LiTFSI-PEO- $\mathrm{Li}_{6} \mathrm{PS}_{5} \mathrm{Cl}$ mixture and the HSEs subsequently formed are referred to as HSE-EMIM and HSE-PP13 respectively. First, the ${ }^{1} \mathrm{H}$ and ${ }^{13} \mathrm{C}$ NMR spectra were measured of the individual components, PEO (solid), EMIM-TFSI (liquid), PP13-TFSI (liquid), HSE-EMIM (solid) and HSE-PP13 (solid) respectively, to compare the structure of these pristine ILs to the ILs embedded in the HSE. As shown in Figure 2c, the ${ }^{1} \mathrm{H}$ resonances of EMIM in HSE-EMIM shows a clear shift, especially for the peak positions between 6 to $10 \mathrm{ppm}$, as compared to pristine EMIM-TFSI. The ${ }^{1} \mathrm{H}$ peaks corresponding to PP13 in HSE-PP13 maintain nearly the same chemical shifts compared to standard PP13-TFSI (Figure 2d). This is not a surprise because EMIM TFSI has a better miscibility with PEO, which in turn influences the ${ }^{1} \mathrm{H}$ environments on the imidazole ring. ${ }^{32}$ Consistently, the ${ }^{13} \mathrm{C}$ CPMAS spectra (Figure $2 \mathbf{e}$ and $\mathbf{f}$ ), indicates less crystalline PEO (located at $72 \mathrm{ppm}$ ) in HSE-EMIM as compared to HSE-PP13. As pristine PEO is mostly crystalline (located at $72 \mathrm{ppm}$ ), the larger amorphous PEO fraction (located at $70 \mathrm{ppm}$ ) seen in the HSE-EMIM provides further confirmation that EMIM has better miscibility with PEO than PP13. ${ }^{33}$ This supports the initial hypothesis that PP13, which has poorer miscibility with PEO will be pushed away from PEO and towards the inorganic $\mathrm{Li}_{6} \mathrm{PS}_{5} \mathrm{Cl}$ particles.

Because Li-metal is the ultimate anode from the perspective of battery energy density, the impact of the IL on the interface of the HSE with Li metal is evaluated in Li-metal symmetrical cells (Li/HSE/Li), both for the HSE-PP13 and HSE-EMIM electrolytes, as shown in Figure 3. The over-potential of the symmetrical battery is an indicative parameter of the interface stability and ability to conduct Li-ions. ${ }^{23}$ In Figure $3 a$, the Li/HSE-EMIM/Li cell shows a continuous increase in over-potential when the current density is higher than $0.05 \mathrm{~mA} / \mathrm{cm}^{2}$, indicating insufficient Li-ion conductivity. In contrast the Li/HSE-PP13/Li cell shows a much more stable over-potential, increasing with current density up to a relatively small value, not exceeding $200 \mathrm{mV}$ at $0.1 \mathrm{~mA} / \mathrm{cm}^{2}$. A similar trend is observed upon cycling, as shown in Figure $\mathbf{3 b}$. The battery with HSE-EMIM shows quick polarization after $300 \mathrm{~h}$ of cycling at a current density of 0.05 $\mathrm{mA} / \mathrm{cm}^{2}$. In comparison the battery with HSE-PP13 shows a very stable over-potential (lower than 200 $\mathrm{mV}$ ) during 800 hours of cycling, indicating a higher ionic conductivity and better interfacial stability against Li-metal. The oxidative stability of both HSE-EMIM and HSE-PP13 were investigated by linearsweep voltammetry (LSV), as shown in Figure 3c. As seen from the LCV scans, HSE-EMIM exhibits higher electrochemical stability of up to $4.75 \mathrm{~V}$, while for the HSE-PP13, oxidation sets in at around $4.5 \mathrm{~V}$. This can be attributed to the phase separation in the HSE-PP13 between PEO and PP13 TFSI where some isolated PEO chains may be easier to oxidize. 
The room temperature conductivity was analyzed using electrochemical impedance spectroscopy (EIS) as shown in Figure $\mathbf{3 d}$ and $\mathbf{e}$. The conductivity of a mixture of LiTFSI-PEO with EMIM TFSI $\left(5.45^{\prime} 10^{-5}\right.$ $\mathrm{S} / \mathrm{cm}$ at $\left.25^{\circ} \mathrm{C}\right)$ is higher than that of the mixture with PP13 TFSI $\left(2.69^{\prime} 10^{-5} \mathrm{~S} / \mathrm{cm}\right.$ at $\left.25^{\circ} \mathrm{C}\right)$ as expected, due to the high miscibility of EMIM TFSI with PEO, which is in good agreement with previous literature. ${ }^{30}$ However, when the $\mathrm{Li}_{6} \mathrm{PS}_{5} \mathrm{Cl}$ is introduced into the system, the opposite result is found. In this case HSEPP13 $\left(1.12^{\prime} 10^{-4} \mathrm{~S} / \mathrm{cm}^{\circ}\right.$ at $\left.25^{\circ} \mathrm{C}\right)$ has a higher conductivity than HSE-EMIM $\left(7.57^{\prime} 10^{-5} \mathrm{~S} / \mathrm{cm}\right.$ at $\left.25^{\circ} \mathrm{C}\right)$, also noting that both the HSEs have a higher conductivity than the materials without $\mathrm{Li}_{6} \mathrm{PS}_{5} \mathrm{Cl}$. Clearly, introduction of the inorganic $\mathrm{Li}_{6} \mathrm{PS}_{5} \mathrm{Cl}$ in the PEO matrix improved the overall conductivity, indicating that the $\mathrm{Li}_{6} \mathrm{PS}_{5} \mathrm{Cl}$ actively contributes to the conductivity. ${ }^{10}$ Moreover, the poorly miscible PP13 ionic liquid, expected to reside at the PEO- $\mathrm{Li}_{6} \mathrm{PS}_{5} \mathrm{Cl}$ interface, results in a higher conductivity of the HSE as compared to the more miscible EMIM ionic liquid which improves the PEO conductivity. This suggests that the nature of the ionic liquid can have a strong impact on the Li-ion transport over the PEO- $\mathrm{Li}_{6} \mathrm{PS}_{5} \mathrm{Cl}$ interface.

\section{Impact of the IL on the interfacial diffusion between LiTFSI-PEO and $\mathrm{Li}_{6} \mathrm{PS}_{5} \mathrm{Cl}$}

To understand the origin of the changes in conductivity of the HSE upon addition of different ionic liquids, as observed in the previous section, 1D and 2D NMR were utilized to examine the contribution of interfacial $\mathrm{Li}^{+}$diffusion in the HSEs. As can be seen in Figure S3, from the $1 \mathrm{D}{ }^{7} \mathrm{Li}$ spectra of the HSEEMIM and HSE-PP13 a clear difference in peak position of the LiTFSI-PEO component could be found, which can be attributed to the varying miscibility of PP13 and EMIM with PEO. This peak is observed at -1.27 ppm in HSE-PP13 and is shifted downfield to -1.17 ppm in HSE-EMIM, which can indicate that Li in LiTFSi-PEO is less shielded by EMIM in its vicinity. Aiming at the unambiguous quantification of the charge transfer over the LiTFSI-PEO- $\mathrm{Li}_{6} \mathrm{PS}_{5} \mathrm{Cl}$ interface, and how this is affected by the addition of ionic liquids, $\left.{ }^{7} \mathrm{Li}\right){ }^{7} \mathrm{Li}$ and ${ }^{6} \mathrm{Li}-{ }^{6} \mathrm{Li}$ 2D NMR EXSY measurements are further conducted on HSE-EMIM and HSEPP13. As seen from Figure S4a and $b$ for HSE-EMIM, no cross peaks are observed with mixing times as long as $2 \mathrm{~s}$, indicating that the $\mathrm{Li}^{+}$diffusion over the LiTFSI-PEO- $\mathrm{Li}_{6} \mathrm{PS}_{5} \mathrm{Cl}$ interface is sluggish. In contrast, very clear cross-peaks corresponding to Li-ion diffusion between the LiTFSI-PEO and $\mathrm{Li}_{6} \mathrm{PS}_{5} \mathrm{Cl}$ phases could be found in HSE-PP13, both for the ${ }^{7} \mathrm{Li}$ and ${ }^{6} \mathrm{Li}$ NMR exchange experiments (Figure 4, Figures S5c and d). This indicates that much better organic-inorganic interfacial Li-ion diffusivity has been realized in the HSE with PP13 TFSI, which rationalizes the enhanced conductivity measured with EIS and the improved electrochemical performance observed for this system.

An advantage offered by solid-state NMR is the ability to quantify $\mathrm{Li}^{+}$diffusion between lithium environments, that manifest with different chemical shifts and have reasonable $T_{1}$ relaxation times. ${ }^{27,28}$ Upon increasing the mixing time, $T_{\text {mix }}$, from $0.1 \mathrm{~s}$ to $1.5 \mathrm{~s}$, and the temperature to $328 \mathrm{~K}$, a clear increase in cross-peak intensity is observed (Figures $4 \mathrm{a}-\mathrm{e}$ ). The evolution of normalized cross-peak intensity as a function of $T_{\text {mix }}$ measured at $288,298,308,318$ and $328 \mathrm{~K}$ within a $T_{\text {mix }}$ range of $0.01 \mathrm{~s}$ to $1.5 \mathrm{~s}$ is depicted in Figure 4f. The Li-ion exchange between the LiTFSI-PEO and $\mathrm{Li}_{6} \mathrm{PS}_{5} \mathrm{Cl}$ phases was quantified 
by fitting the evolution of the cross-peak intensity as a function of $\mathrm{T}_{\text {mix }}$ to a diffusion model derived from Fick's law, which has been described by us in detail elsewhere and also further described in supplement information. ${ }^{27,28,34}$ From the fit, the diffusion coefficient (D) as a function of temperature can be obtained, which in this case reflects Li-ion diffusion across the LiTFSI-PEO- $\mathrm{Li}_{6} \mathrm{PS}{ }_{5} \mathrm{Cl}$ interface. The diffusion coefficients as a function of temperature obtained from the fit are given in Figure $\mathbf{4 f}$. The diffusion data for LiTFSI-PEO- $\mathrm{Li}_{6} \mathrm{PS}_{5} \mathrm{Cl}$ can be fit with an Arrhenius law, yielding an activation energy of $0.126 \mathrm{eV}$. This energy barrier between organic and inorganic components is much lower than that reported in literature measured with impedance, ${ }^{24,25}$ which indicates that by addition of the PP13 TFSI ionic liquid, the LiTFSI-PEO- $\mathrm{Li}_{6} \mathrm{PS}_{5} \mathrm{Cl}$ interface is 'activated' even when micron sized inorganic argyrodite filler particles are used in the HSE providing a limited ionic contact area, as for instance compared to nano-fillers.

\section{Role of the IL in the interface structure and Li-ion mobility}

To understand the role of the ionic liquid in activating the LiTFSI-PEO- $\mathrm{Li}_{6} \mathrm{PS}_{5} \mathrm{Cl}$ interface, the interface structure was further explored using NMR. 2D ${ }^{1} \mathrm{H}-{ }^{-1} \mathrm{H}$ nuclear overhauser effect spectroscopy (NOESY) measurements, which were performed on both the HSE-PP13 and HSE-EMIM at different mixing times as shown in Figure 5 and Figure S5. The cross peaks that arise, especially for short mixing times, are typically between protons that are in close spatial proximity to each other. For this reason, NOESY is a commonly used method to elucidate polymer structures and configurations. ${ }^{35}$ As seen from the dotted region Figure S5a-c, all the cross peaks between EMIM TFSI and LiTFSI-PEO appear at nearly at the same mixing time which means that there is no preferred orientation of the EMIM TFSI species with respect to PEO. This confirms the earlier finding that these species mix well, and that the EMIM TFSI is mobile within the HSE-EMIM showing no preferred orientation. Interestingly for the HSE-PP13 in Figures 5a-c, the dotted region displays a sequence of cross peak that evolves with increasing mixing times. At the shortest mixing times, ${ }^{1} \mathrm{H}-{ }^{1} \mathrm{H}$ correlations are first observed between ${ }^{1} \mathrm{H}$ resonances at positions a and $\mathrm{b}$ on the piperidene ring (shown in Figure 5a) of PP13 TFSI and the $-\mathrm{OCH}_{2}$ - protons from PEO. These ring protons are the furthest away from the bulky propyl and methyl groups attached to the $\mathrm{N}$ atom on the piperidene ring. This implies that the positively charged $\mathrm{N}$ atom on the piperidene ring, along with the functional groups it carries, are oriented away from the PEO segments. A detailed buildup of cross peaks intensity of the protons belonging to EMIM and PP13 correlated to the $-\mathrm{OCH} 2-$ protons of PEO is provided in Figure s6.

After identifying the orientation of the PP13 TFSI IL with respect to the PEO chains, the interface between $\mathrm{PEO}$ and $\mathrm{Li}_{6} \mathrm{PS}_{5} \mathrm{Cl}$ is further probed using ${ }^{1} \mathrm{H}-{ }^{7} \mathrm{Li}$ CPMAS experiments. (Figures $5 \mathbf{e}$ and $\mathrm{f}$ ). For both the HSE-EMIM and HSE-PP13, the ${ }^{1} \mathrm{H}-{ }^{7} \mathrm{Li}$ CP MAS NMR spectra show two Li environments that are related to the interface and one to LiTFSI-PEO, which varies in intensity as the contact time increases, as shown in the Figure $\mathbf{5 g}$. Cross polarization depends on the heteronuclear dipolar interactions between ${ }^{1} \mathrm{H}$ and ${ }^{7} \mathrm{Li}$, 
thus is typically most efficient when these species are in close proximity to each other. ${ }^{10}$ This indicates that the observed ${ }^{7} \mathrm{Li}$ environment is in close spatial proximity to the proton rich polymer phase of the HSE. An interesting observation is that for HSE-PP13 the intensity of the peak assigned to the interface environment builds up quickly to a maximum intensity at a contact time of $2 \mathrm{~ms}$, after which the intensity of the peak assigned to the interface steadily decreases with increasing CP contact times. This may indicate that locally the Li-ions are more mobile, which weakens the ${ }^{1} \mathrm{H}-{ }^{7} \mathrm{Li}$ dipolar interaction making the cross polarization less efficient.

Based on the ${ }^{7} \mathrm{Li}$ and ${ }^{1} \mathrm{H}$ NMR experiments, we propose that the EMIM TFSI is trapped within the polymer phase and is not in direct contact with the $\mathrm{Li}_{6} \mathrm{PS}_{5} \mathrm{Cl}$ phase (Figure 6a). In contrast, PP13 TFSI which is not miscible in the PEO, settles at the interface with the LPSC phase (Figure 6a), where the positive charged nitrogen appears to be in direct contact with LPSC. When the IL is in contact with the inert interfacial environment between $\mathrm{Li}_{6} \mathrm{PS}_{5} \mathrm{Cl}$ and $\mathrm{PEO}$, the $\mathrm{Li}^{+}$diffusion at phase boundaries may be improved. This could occur due to a higher local mobility but also by the higher dielectric constant of IL $(\epsilon>20)$ compared to PEO $(€ \sim 5) .{ }^{36}$ This higher dielectric constant enhances the local polarizability which supports a higher diffusivity.

These results indicate that in the LiTFSI-PEO $\mathrm{Li}_{6} \mathrm{PS}_{5} \mathrm{Cl} \mathrm{HSE}$, the diffusion over the interface between the $\mathrm{PEO}$ and $\mathrm{Li}_{6} \mathrm{PS}_{5} \mathrm{Cl}$ phase limits the conductivity as it prevents the high conductivity of the LPSC phase from being utilized. Since this barrier is overcome by the addition of PP13 TFSI IL, it can be argued that the overall conductivity of the HSE is now only limited by the $\mathrm{Li}^{+}$conductivity in the polymer phase. To address this, an HSE is prepared with both the PP13 TFSI and EMIM TFSI IL additives. In this HSE, PP13 TFSI is expected to improve the interfacial $\mathrm{Li}^{+}$diffusivity while EMIM TFSI is expected to influence $\mathrm{Li}^{+}$ diffusivity in the PEO phase. Indeed, the small fraction of a IL (PP13 TFSI and EMIM TFSI, 0.25:1 molar ratio IL: $\mathrm{Li}^{+}$) enabled a further enhanced ionic conductivity of $2.47^{\prime} 10^{-4} \mathrm{~S} / \mathrm{cm}$ at $25^{\circ} \mathrm{C}$ compared with single IL added in Figure $3 e$. Moreover, as can be seen from Figure $6 \mathrm{~b}$, the critical current density of the symmetrical battery with the HSE when both ionic liquids are added is further improved to $0.25 \mathrm{~mA} / \mathrm{cm}^{2}$ when measured at room temperature, which is much higher than batteries measured with individual ionic liquid additives $\left(0.1 \mathrm{~mA} / \mathrm{cm}^{2}\right)$ when the same fraction of additive was used (Figure $3 a$ ). In theory, a critical current density of $0.25 \mathrm{~mA} / \mathrm{cm}^{2}$ could already enable a solid-state battery using Li-S as cathode of over $500 \mathrm{Wh} / \mathrm{kg} .{ }^{37}$ We further compared the critical current density obtained of this HSE with those reported in open literature as shown in Table S1. It can be seen that the HSE with both ionic liquids added demonstrates one of the highest critical current densities observed among state-of-the-art solid state electrolytes, although realizing this is achieved by a small fraction of an IL phase. In the end, the resulted HSE was tested electrochemically in a Li-ion battery combining a Li-metal anode and a $\mathrm{LiFePO}_{4}(\mathrm{LFP})$ cathode (Li/HSE/LFP), as shown in Figure $6 \mathrm{c}-\mathrm{d}$. The battery provides a capacity of over $0.8 \mathrm{mAh}$ (120 $\mathrm{mAh} / \mathrm{g}$ ) after 50 cycles, with an average Coulombic efficiency of $~ 99.9 \%$ and an over potential of 150 $\mathrm{mV}$, indicating the promising feasibility of the HSE to serve as a solid-state electrolyte for a room temperature LMB. 
In conclusion, we propose that the bottleneck for $\mathrm{Li}^{+}$transport in HSEs comprising of PEO polymer and inorganic solid electrolyte phases is across the phase boundaries, where the presence of decomposition products results in a deficiency of ether oxygen species that are responsible for Li-ion conductivity. The interface diffusivity can be improved by making use of an ionic liquid additive as a wetting agent, when its miscibility in PEO is poor like for PP13 TFSI, forcing it to be positioned at the phase boundaries where it functions as a bridge for Li-ion transport. In contrast, an ionic liquid electrolyte that is miscible in PEO, such as EMIM TFSI, improves the conductivity of the PEO as it is distributed between the PEO chains inducing higher chain and Li-ion mobility. However, in this case the interface remains the bottleneck for Liion transport. A detailed investigation provides insight into the structure of the interface between the organic and inorganic phases in the HSE and its role in $\mathrm{Li}^{+}$transport. This allows the development of interface strategies, such as the one proposed with non-miscible ionic liquids, leading to highly improved conductivities, and thus compatibility with Li-metal anodes. Multi-nuclear NMR proves to be a very versatile and powerful method to reveal these processes especially in HSEs. Future work will include the investigation of the salt concentration, inorganic surface modification and the role of space charges to the interfaces as well as to the HSEs as a whole, shedding more light on potential next generation solid electrolytes.

\section{Experimental Section}

The solid-state electrolyte $\mathrm{Li}_{6} \mathrm{PS}_{5} \mathrm{Cl}$ was prepared by a simple solid-state reaction. The stoichiometric raw materials $\mathrm{LiCl}$ (Sigma-Aldrich), $\mathrm{P}_{2} \mathrm{~S}_{5}$ (Sigma-Aldrich), and $\mathrm{Li}_{2} \mathrm{~S}$ (Sigma-Aldrich) were used as the starting materials and were ball milled at $110 \mathrm{rpm}, 2 \mathrm{hrs}$ with the $\mathrm{ZrO}_{2}$ coated jars using $18 \mathrm{ZrO}_{2}$ balls. After the ball milling, the precursor was sealed in a quartz tube with Ar and then annealed at $550^{\circ} \mathrm{C}$ for 15 hours to obtain the $\mathrm{Li}_{6} \mathrm{PS}_{5} \mathrm{Cl}$ solid electrolyte.

Hybrid solid electrolyte (HSE) films were prepared by mixing $0.768 \mathrm{~g}$ PEO (Sigma-Aldrich, $\mathrm{M}_{\mathrm{w}}=600,000$ ), $0.28 \mathrm{~g} \mathrm{LiTFSI}$ (Sigma-Aldrich), $0.1048 \mathrm{~g} \mathrm{Li}_{6} \mathrm{PS}_{5} \mathrm{Cl}$ and $0.25: 1$ molar ratio $\mathrm{L}^{2} \mathrm{Li}^{+}$of ionic liquid together in $10 \mathrm{ml}$ acetonitrile (Sigma-Aldrich) and stirring for $24 \mathrm{~h}$. The prepared solution was evenly casted on a Teflon plate and dried in the glove box at room-temperature for $24 \mathrm{~h}$, then transfer into vacuum environment in glove box for $48 \mathrm{~h}$.

The LSV curves were recorded from OCV to $5.5 \mathrm{~V}$ versus $\mathrm{Li} / \mathrm{Li}^{+}$at a scanning rate of $0.1 \mathrm{mV} \mathrm{s}^{-1}$ using an Autolab (PGSTAT302N). The ionic conductivities of the HSEs were measured by EIS where the HSE is sandwiched between two stainless steel blocking electrodes, kept at each test temperature (from 25 to 85 ${ }^{\circ} \mathrm{C}$ ) for at least half an hour before the electrochemical impedance measurements were acquired, in order to reach thermal equilibrium. The EIS measurements were carried out from $100 \mathrm{kHz}$ to $1 \mathrm{~Hz}$. The HSEbased all-solid-state cells were assembled in an Ar-filled glove box. These cells consisted of of lithium metal (Aldrich, $95 \% \mathrm{wt} \%{ }^{6} \mathrm{Li}$ and $5 \% \mathrm{wt} \%{ }^{7} \mathrm{Li}$ ) or $\mathrm{LiFePO}_{4}$ (mass loading: $\sim 6.5 \mathrm{mg} / \mathrm{cm}^{2}$ ) as electrodes, and the HSE as the electrolyte. It should be noted that $50 \mathrm{uL}$ of the HSE solution prepared with above methods 
was dropped into LFP electrode and then fully dry. Charge-discharge tests of the HSE-based all-solid-state cells were carried out using a Maccor 4000 battery cycler at room temperature.

Solid-state NMR measurements were performed on a Bruker Ascend 500 magnet $\left(B_{0}=11.7 \mathrm{~T}\right)$ with a NEO console operating at frequencies of $500.130 \mathrm{MHz}$ for ${ }^{1} \mathrm{H}, 194.37 \mathrm{MHz}$ for ${ }^{7} \mathrm{Li}, 73.6 \mathrm{MHz}$ for ${ }^{6} \mathrm{Li}$ and 125.758 for ${ }^{13} \mathrm{C}$. ${ }^{6,7} \mathrm{Li}$ chemical shifts were referenced with respect a $0.1 \mathrm{M} \mathrm{LiCl}$ solution $(0 \mathrm{ppm})$ and ${ }^{1} \mathrm{H}$ and ${ }^{13} \mathrm{C}$ chemical shifts were referenced with respect to solid adamantane $\left({ }^{1} \mathrm{H}\right.$ at $1.81 \mathrm{ppm}$ and ${ }^{13} \mathrm{C}$ at $38.48 \mathrm{ppm}$ ). A Bruker three channel MAS $4 \mathrm{~mm}$ DVT probe was used for all measurements. The LiTFSIPEO- $\mathrm{Li}_{6} \mathrm{PS}{ }_{5} \mathrm{Cl}(\mathrm{HSE}), \mathrm{HSE}-\mathrm{EMIM}$, and HSE-PP13 membranes were cut into tiny pieces and filled in $4 \mathrm{~mm}$ zirconia rotors, which were spun at spinning speeds of $5 \mathrm{kHz}$ for all measurements. One pulse ${ }^{1} \mathrm{H},{ }^{7} \mathrm{Li}$ and ${ }^{6} \mathrm{Li}$ experiments were performed with $\mathrm{p} / 2$ pulse lengths of $3.5,2.7$, and $4.75 \mathrm{~ms}$ respectively. A recycle delay of three times of $T_{1}$ was used each time, where $T_{1}$ was determined using saturation recovery experiments. Two-dimensional (2D) ${ }^{7} \mathrm{Li}-{ }^{7} \mathrm{Li}$ and ${ }^{6} \mathrm{Li}-{ }^{6} \mathrm{Li}$ exchange spectroscopy (EXSY) measurements were performed for these samples at various mixing times from $1 \mathrm{~ms}$ up to $2 \mathrm{~s}$ and at temperatures from 10 to $50 \otimes C$. Each spectrum consisted of 8(16) scans for each of the 1200-1500 (400-800) transients, each transient incremented by $200(400) \mathrm{ms}$ with a recycle delay of up to $5(10) \mathrm{s}$. The ${ }^{7} \mathrm{Li}\left({ }^{6} \mathrm{Li}\right) \mathrm{CPMAS}$ experiments were performed with an initial ${ }^{1} \mathrm{H}$ p/2 pulse of $5 \mathrm{~ms}$. During cross polarization, for ${ }^{7} \mathrm{Li}\left({ }^{6} \mathrm{Li}\right)$, if field strengths of $28(25) \mathrm{kHz}$ and contact times of up to $10 \mathrm{~ms}$ were utilized. The if field amplitude of ${ }^{1} \mathrm{H}$ during CP was ramped from 70 to $100 \%$. 1024 scans were acquired for each sample with a recycle delay of 2(3) s. $2 \mathrm{D}^{1} \mathrm{H}-6 \mathrm{Li}$ heteronuclear correlation (HETCOR) measurements were performed with a short $\mathrm{CP}$ contact time of $0.2 \mathrm{~ms}$. For each of the 128 transients in the indirect ${ }^{1} \mathrm{H}$ dimension, $128{ }^{6} \mathrm{Li}$ scans were accumulated. A recycle delay of $3 \mathrm{~s}$ was applied after each scan. The ${ }^{13} \mathrm{C}$ CPMAS experiments were measured with an initial ${ }^{1} \mathrm{H} \mathrm{p} / 2$ pulse of $3.65 \mathrm{~ms}$. During cross polarization for ${ }^{13} \mathrm{C}$, an if field strengths of $58 \mathrm{kHz}$ was utilized. 40000 scans were acquired for each sample with a recycle delay of $2 \mathrm{~s}$. For both the CPMAS and HETCOR experiments, proton decoupling was performed during acquisition using the SPINAL-64 decoupling sequence ${ }^{38}$. 2D ${ }^{1} \mathrm{H}-{ }^{1} \mathrm{H}$ NOESY measurements were performed at various mixing times from $1 \mathrm{~ms}$ to $100 \mathrm{~ms}$ at room temperature. Each spectrum consisted of 8 scans for each of the 800 transients, each transient incremented by $100 \mathrm{~ms}$ with a recycle delay of $2 \mathrm{~s}$.

\section{Declarations}

\section{Acknowledgements}

The authors thank Frans Ooms for his assistance with experiments. Financial support is greatly acknowledged from the Netherlands Organization for Scientific Research (NWO) under the VICl grant nr. 16122. Financial support from the Advanced Dutch Energy Materials (ADEM) program of the Dutch Ministry of Economic Affairs, Agriculture and Innovation is gratefully acknowledged.

\section{Reference}


1 Armand, M. \& Tarascon, J.-M. Building better batteries. Nature 451, 652-657 (2008).

2 Dunn, B., Kamath, H. \& Tarascon, J.-M. Electrical energy storage for the grid: a battery of choices. Science 334, 928-935 (2011).

3 Cheng, X. B., Zhao, C. Z., Yao, Y. X., Liu, H. \& Zhang, Q. Recent Advances in Energy Chemistry between Solid-State Electrolyte and Safe Lithium-Metal Anodes. Chem 5, 74-96 (2019).

4 Zaman, W., Hortance, N., Dixit, M. B., De Andrade, V. \& Hatzell, K. B. Visualizing percolation and ion transport in hybrid solid electrolytes for Li-metal batteries. J Mater Chem A 7, 23914-23921 (2019).

5 Armand, M. The history of polymer electrolytes. Solid State Ionics 69, 309-319 (1994).

6 Bouchet, R. et al. Single-ion BAB triblock copolymers as highly efficient electrolytes for lithiummetal batteries. Nat Mater 12, 452-457 (2013).

$7 \quad$ Ma, Q. et al. Single lithium-ion conducting polymer electrolytes based on a super-delocalized polyanion. Angew Chem Int Edit 55, 2521-2525 (2016).

8 Dixit, M. B. et al. Scalable Manufacturing of Hybrid Solid Electrolytes with Interface Control. Acs App/ Mater Inter 11, 45087-45097 (2019).

9 Osada, I., de Vries, H., Scrosati, B. \& Passerini, S. Ionic-liquid-based polymer electrolytes for battery applications. Angew Chem Int Edit 55, 500-513 (2016).

10 Liu, M. et al. Tandem Interface and Bulk Li-Ion Transport in a Hybrid Solid Electrolyte with Microsized Active Filler. Acs Energy Lett 4, 2336-2342 (2019).

11 Croce, F., Sacchetti, S. \& Scrosati, B. Advanced, lithium batteries based on high-performance composite polymer electrolytes. J Power Sources 162, 685-689 (2006).

12 Syzdek, J. et al. Ceramic-in-polymer versus polymer-in-ceramic polymeric electrolytes-A novel approach. J Power Sources 194, 66-72 (2009).

13 Hassoun, J. \& Scrosati, B. A high-performance polymer tin sulfur lithium ion battery. Angew Chem Int Edit 49, 2371-2374 (2010).

14 Płcharski, J. \& Weiczorek, W. PEO based composite solid electrolyte containing nasicon. Solid State lonics 28, 979-982 (1988).

$15 \mathrm{Xu}, \mathrm{K}$. Electrolytes and interphases in Li-ion batteries and beyond. Chem Rev 114, 11503-11618 (2014).

16 Zheng, J., Tang, M. X. \& Hu, Y. Y. Lithium lon Pathway within $\mathrm{Li}_{7} \mathrm{La}_{3} \mathrm{Zr}_{2} \mathrm{O}_{12}$-Polyethylene Oxide Composite Electrolytes. Angew Chem Int Edit 55, 12538-12542, (2016). 
17 Wang, S. et al. A dendrite-suppressed flexible polymer-in-ceramic electrolyte membrane for advanced lithium batteries. Electrochim Acta 353 (2020).

18 Fergus, J. W. Ceramic and polymeric solid electrolytes for lithium-ion batteries. J Power Sources 195, 4554-4569 (2010).

19 Blanga, R., Burstein, L., Berman, M., Greenbaum, S. \& Golodnitsky, D. Solid polymer-in-ceramic electrolyte formed by electrophoretic deposition. J Electrochemical Soc 162, D3084-D3089 (2015).

20 Chen, L. et al. PEO/garnet composite electrolytes for solid-state lithium batteries: From "ceramic-inpolymer" to "polymer-in-ceramic". Nano Energy 46, 176-184 (2018).

21 Huo, H. Y. et al. Rational Design of Hierarchical "Ceramic-in-Polymer" and "Polymer-in-Ceramic" Electrolytes for Dendrite-Free Solid-State Batteries. Adv Energy Mater 9 (2019).

22 Bonizzoni, S. et al. NASICON-type polymer-in-ceramic composite electrolytes for lithium batteries. PhyChem Cheml Phy 21, 6142-6149 (2019).

23 Dixit, M. B. et al. Nanoscale Mapping of Extrinsic Interfaces in Hybrid Solid Electrolytes. Joule 4, 207-211 (2020).

24 Simon, F. J. et al. Properties of the interphase formed between argyrodite-type $\mathrm{Li}_{6} \mathrm{PS}_{5} \mathrm{Cl}$ and polymer-based PEO $_{10}$ : LiTFSI. Acs Appl Mater Inter 11, 42186-42196 (2019).

25 Simon, F. J., Hanauer, M., Richter, F. H., Janek, Interphase Formation of PEO20: LiTFSI-Li ${ }_{6} \mathrm{PS}_{5} \mathrm{Cl}$ Composite Electrolytes with Lithium Metal. Acs App/ Mater Inter 12, 11713-11723 (2020).

26 Zheng, J., Wang, P., Liu, H. \& Hu, Y.-Y. Interface-enabled ion conduction in $\mathrm{Li}_{10} \mathrm{GeP}_{2} \mathrm{~S}_{12}$-poly (ethylene oxide) hybrid electrolytes. ACS Appl Energy Mater 2, 1452-1459 (2019).

$27 \mathrm{Yu}, \mathrm{C}$. et al. Accessing the bottleneck in all-solid state batteries, lithium-ion transport over the solidelectrolyte-electrode interface. Nat Commun 8, 1086, doi:10.1038/s41467-017-01187-y (2017).

28 Ganapathy, S., Yu, C., van Eck, E. R. H. \& Wagemaker, M. Peeking across Grain Boundaries in a Solid-State lonic Conductor. Acs Energy Lett 4, 1092-1097 (2019).

29 Rataboul, F. et al. Molecular Understanding of the Formation of Surface Zirconium Hydrides upon Thermal Treatment under Hydrogen of [(: $\left.\mathrm{SiO}) \mathrm{Zr}\left(\mathrm{CH}_{2} \mathrm{tBu}\right)_{3}\right]$ by Using Advanced Solid-State NMR Techniques. J Am Chem Soc 126, 12541-12550 (2004).

30 Zhu, C., Cheng, H. \& Yang, Y. Electrochemical characterization of two types of PEO-based polymer electrolytes with room-temperature ionic liquids. J Electrochemical Soc, 155, A569 (2008). 
31 Kodama, K. et al. Structural effects of polyethers and ionic liquids in their binary mixtures on lower critical solution temperature liquid-liquid phase separation. Polymer J 43, 242-248 (2011).

32 Cesare Marincola, F. et al. NMR Investigation of Imidazolium-Based lonic Liquids and Their Aqueous Mixtures. ChemPhysChem 13, 1339-1346 (2012).

33 Wang, B.-H., Xia, T., Chen, Q. \& Yao, Y.-F. J. P. Probing the Dynamics of $\mathrm{Li}^{+}$Ions on the Crystal Surface: A Solid-State NMR Study. Polymers 12, 391 (2020).

34 Ganapathy, S., van Eck, E. R., Kentgens, A. P., Mulder, F. M. \& Wagemaker, M. Equilibrium LithiumIon Transport Between Nanocrystalline Lithium-Inserted Anatase $\mathrm{TiO}_{2}$ and the Electrolyte. Chem-A European J 17, 14811-14816 (2011).

35 Zhao, Z. et al. Ionic-Association-Assisted Viscoelastic Nylon Electrolytes Enable Synchronously Coupled Interface for Solid Batteries. Adv Func Mater 30, 2000347 (2020).

36 Kumar, M. \& Sekhon, S. Role of plasticizer's dielectric constant on conductivity modification of PEO- $\mathrm{NH}_{4} \mathrm{~F}$ polymer electrolytes. European Polymer J38, 1297-1304 (2002).

37 Liu, M. et al. Novel gel polymer electrolyte for high-performance lithium-sulfur batteries. Nano Energy 22, 278-289 (2016).

38 Fung, B., Khitrin, A. \& Ermolaev, K. An improved broadband decoupling sequence for liquid crystals and solids. J Magnetic Resonance 142, 97-101 (2000).

\section{Figures}


(a)

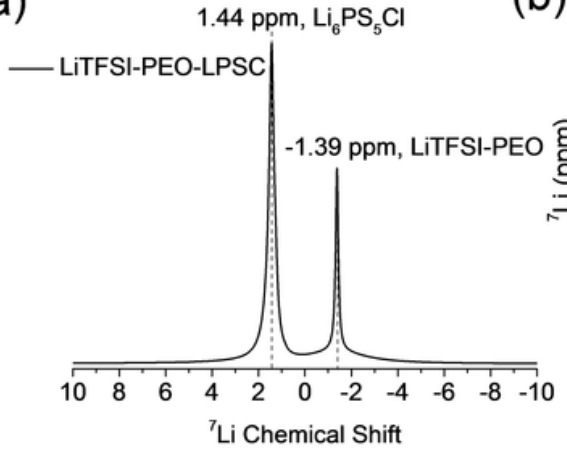

(d)

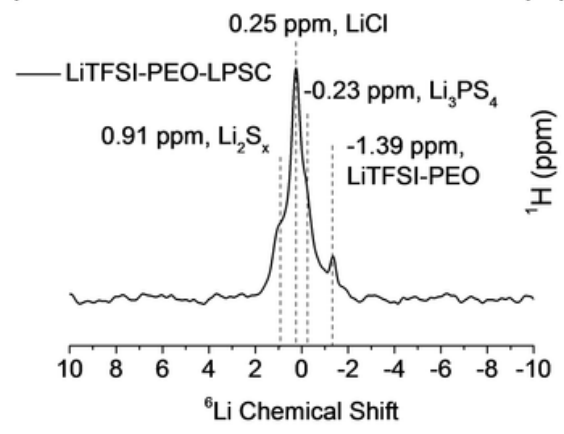

(b)

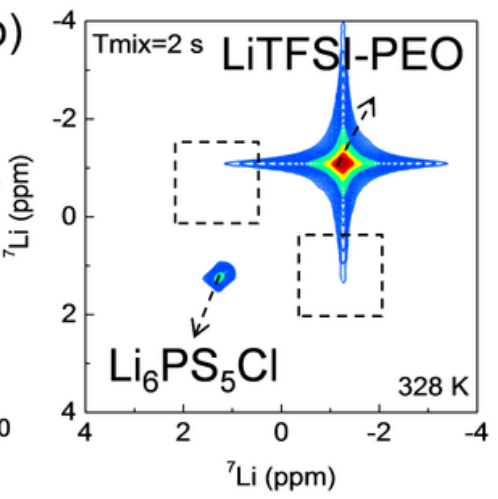

(e) 0.0

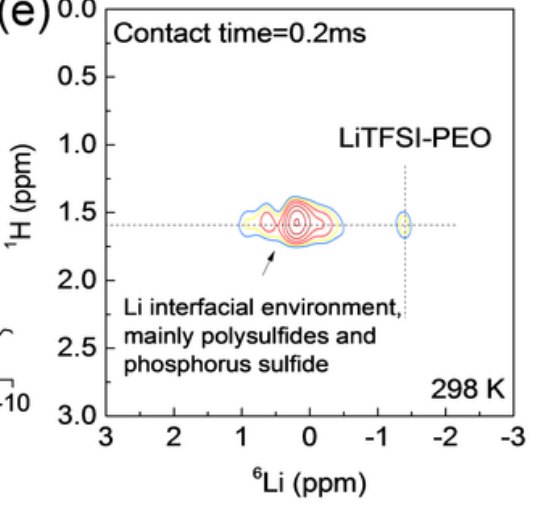

(c)

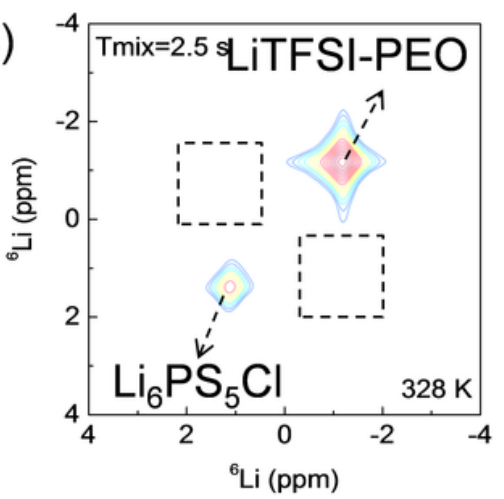

(f)

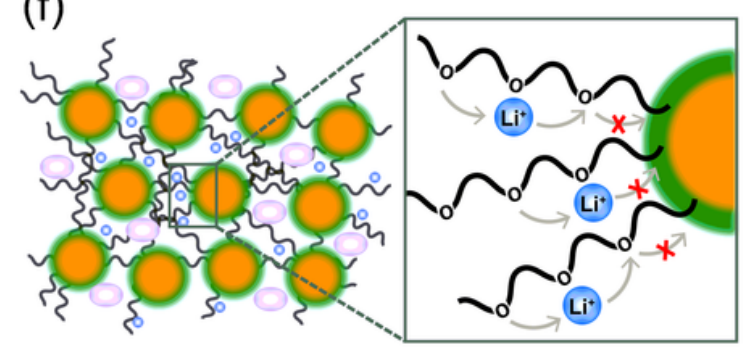

TFSI (Li) ${ }_{0} \frown{ }_{0}$ PEO

\section{Figure 1}

Li+ interphase diffusion between LiTFSI-PEO and Li6PS5Cl (a-c) One-dimensional (1D) (a) 7Li magic angle spinning (MAS) spectrum and two-dimensional (2D) (b) 7Li-7 Li and (c) 6Li-6Li exchange spectra (2D-EXSY) corresponding to the Li6PS5Cl -LiTFSI-PEO HSE with mixing times of 2 and $2.5 \mathrm{~s}$ at $328 \mathrm{~K}$, where no obvious off-diagonal cross-peak intensity is observed, indicating that the exchange flux of Liions over the solid-solid Li6PS5Cl - LiTFSI-PEO interface is very small. (d) 1D 6Li CPMAS spectrum with a contact time of $6 \mathrm{~ms}$, measured at a spinning speed of $5 \mathrm{kHz}$. 1024 scans were acquired with a recycle delay of $20 \mathrm{~s}$. (e) A 2D 1H-6Li heteronuclear correlation (HETCOR) spectrum measured with a CP contact time of $0.2 \mathrm{~ms}$. (f) Schematic figure of Li+ diffusion pathway in the HSE. 
(a)

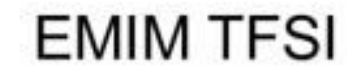

CO

(c)

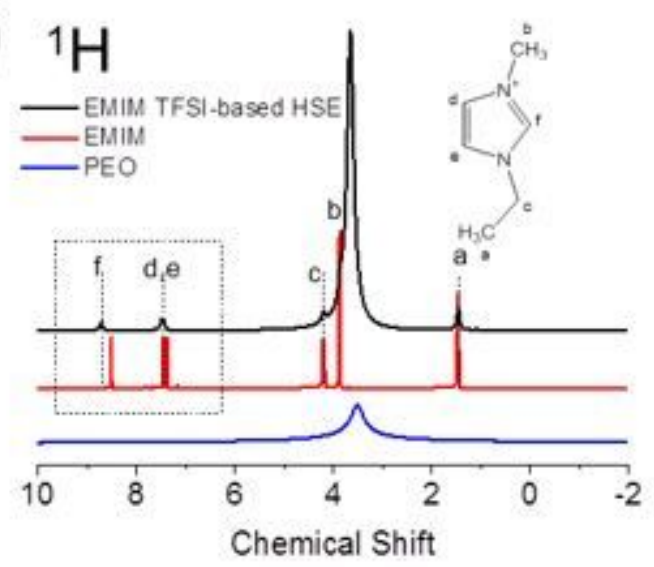

(e)

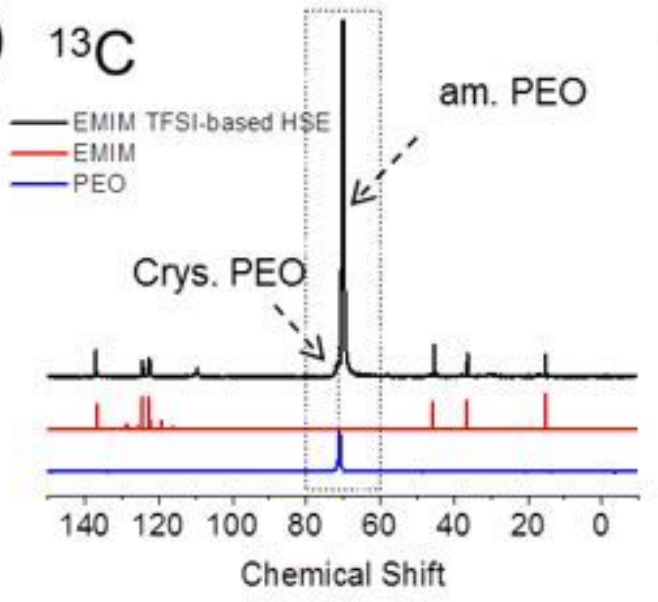

(b) PP13 TFSI

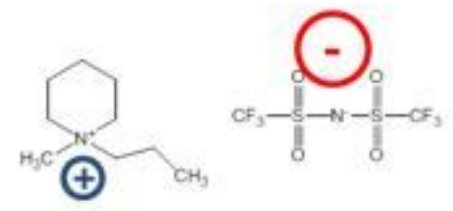

(d)

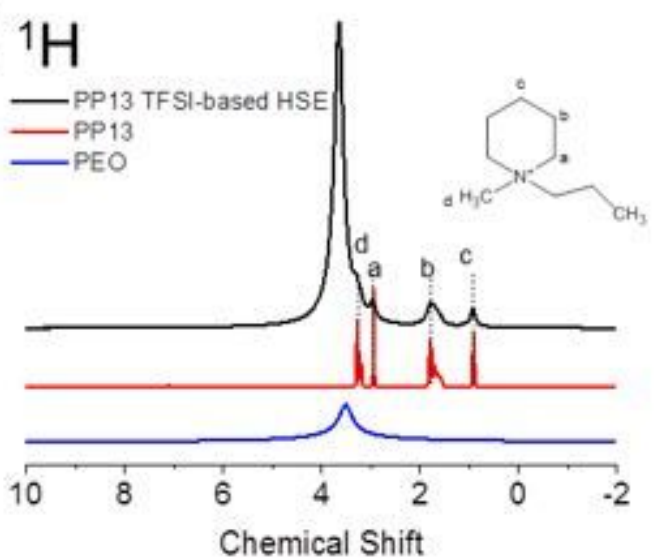

(f)

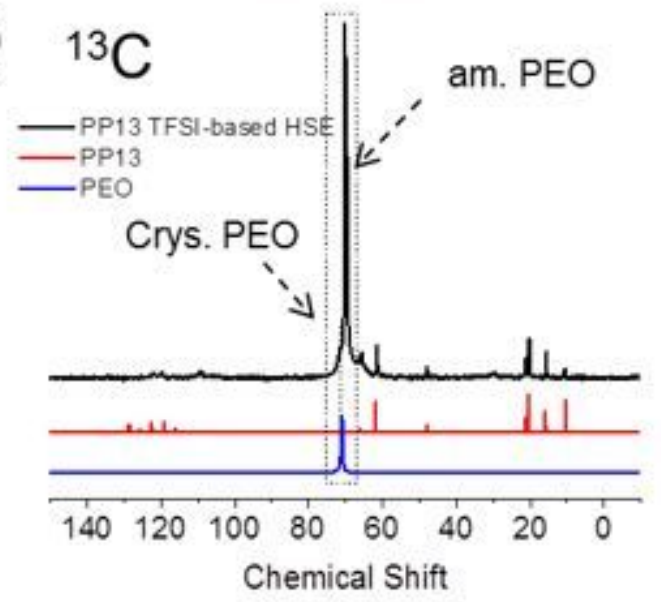

Figure 2

Structural characterization of HSE with PP13 TFSI and EMIM TFSI ionic liquids additives. (a, b) Molecular structure of PP13 TFSI and EMIM TFSI ionic liquids. (c, d) 1D 1H spectra of LiTFSI-PEO- Li6PS5CI HSE with PP13 TFSI and EMIM TFSI ionic liquids. (e, f) 13C Cross polarization (CP) MAS spectra of LiTFSIPEO- Li6PS5CI HSE with PP13 TFSI and EMIM TFSI ionic liquids. 

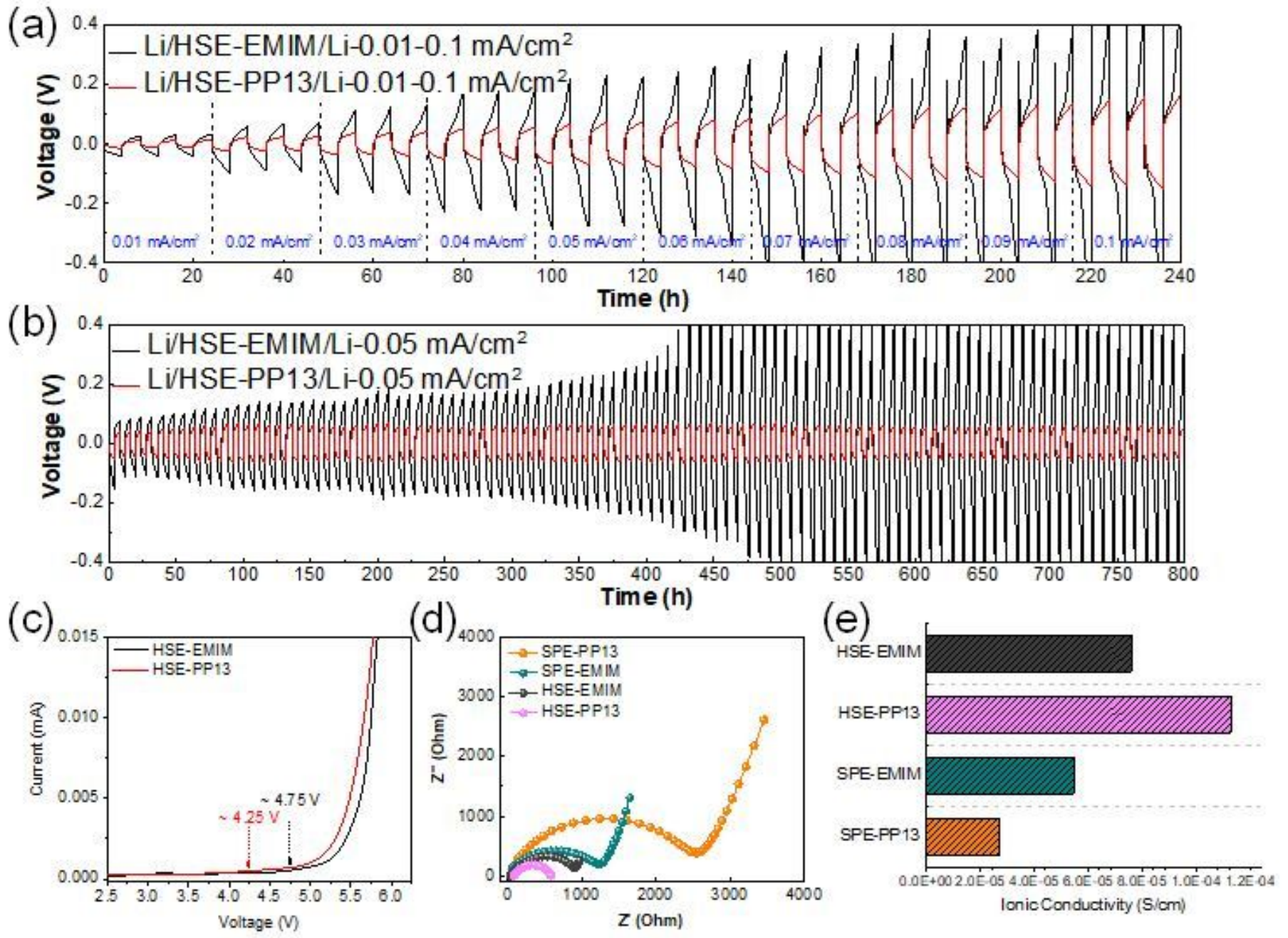

\section{Figure 3}

Electrochemical characterization of HSE with PP13 TFSI and EMIM TFSI ionic liquid additives $(a, b)$ Charge and discharge curves of a Li metal symmetrical cell with LiTFSI-PEO- Li6PS5CI HSEs with PP13 TFSI and EMIM TFSI ionic liquids. (c, d) Linear-sweep voltammetry (LSV) and electrochemical impedance spectroscopy measurements (EIS) of battery with LiTFSI-PEO solid polymer electrolytes with PP13 TFSI (SPE-PP13) and EMIM TFSI (SPE-EMIM) ionic liquids, and LiTFSI-PEO- Li6PS5CI HSEs with PP13 TFSI (HSE-PP13) and EMIM TFSI (HSE-EMIM) ionic liquids. (e) lonic conductivity of LiTFSI-PEO SPEs with PP13 TFSI (SPE-PP13) and EMIM TFSI (SPE-EMIM) ionic liquids, and LiTFSI-PEO- Li6PS5CI HSEs with PP13 TFSI (HSE-PP13) and EMIM TFSI (HSE-EMIM) ionic liquids. 

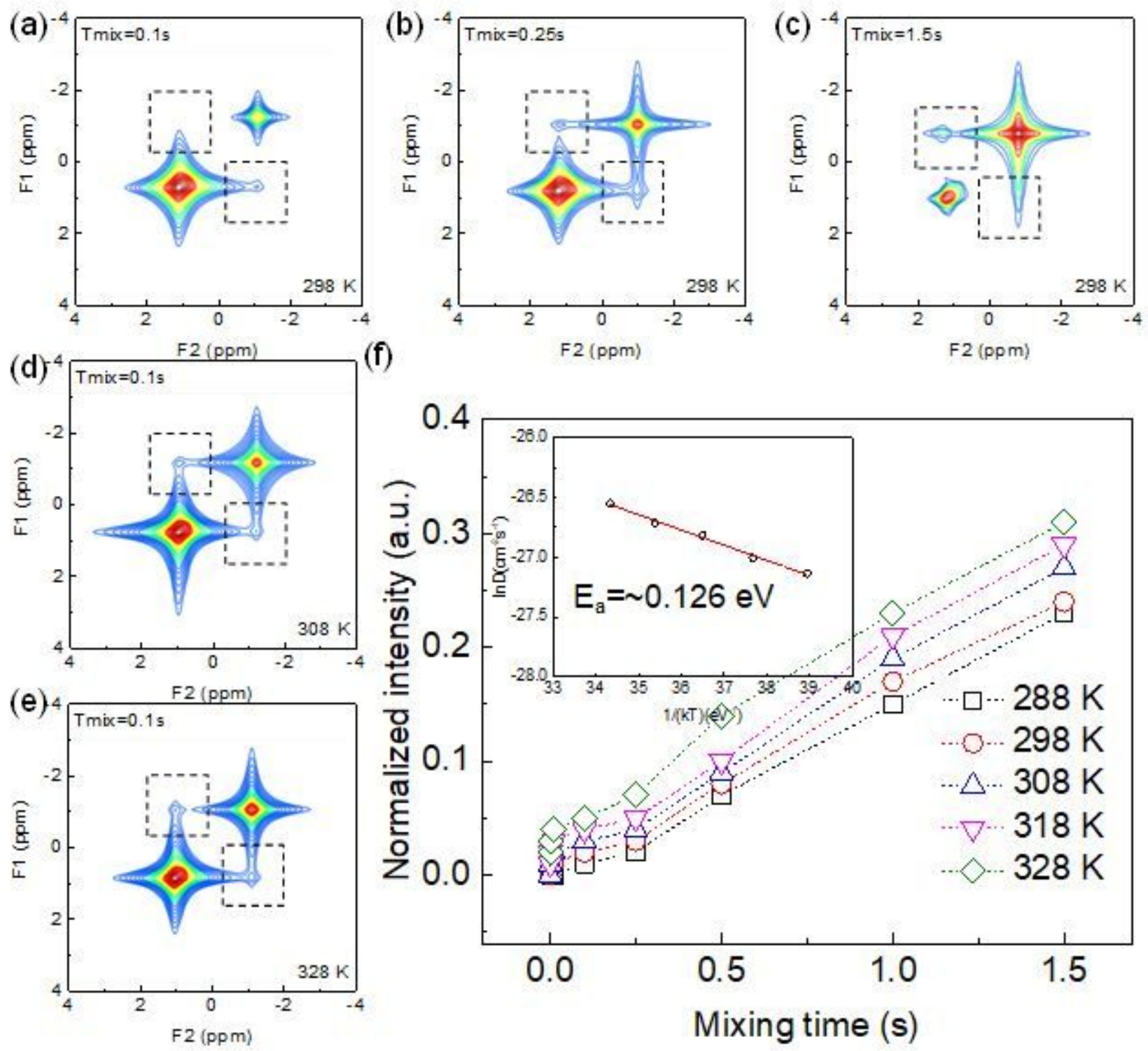

\section{Figure 4}

Quantification of Li+ diffusion across phase boundaries in the HSE with the PP13 TFSI ionic liquid. (a-e) 2D 7Li-7Li EXSY spectra of the mixture of LiTFSI-PEO- Li6PS5Cl with PP13 TFSI ionic liquid measured at spinning speed of $5 \mathrm{kHz}$ at (a-c) $298 \mathrm{~K}$ with mixing times Tmix of $0.1,0.25$ and $1.5 \mathrm{~s}$, and (d,e) at 308 and $328 \mathrm{~K}$ with a Tmix of $0.1 \mathrm{~s}$. (f) Evolution of cross-peak intensity as a function of Tmix obtained from the 2D-EXSY measurements done at the temperatures indicated in the graph. The line passing through the symbols is a guide to the eye. Inset figure is the dependence of the diffusion coefficient obtained from fitting the data in (f) to a diffusion model given in our previous literature.28 These can be fit with the Arrhenius law, yielding an activation energy (Ea) of $0.126 \mathrm{eV}$. 

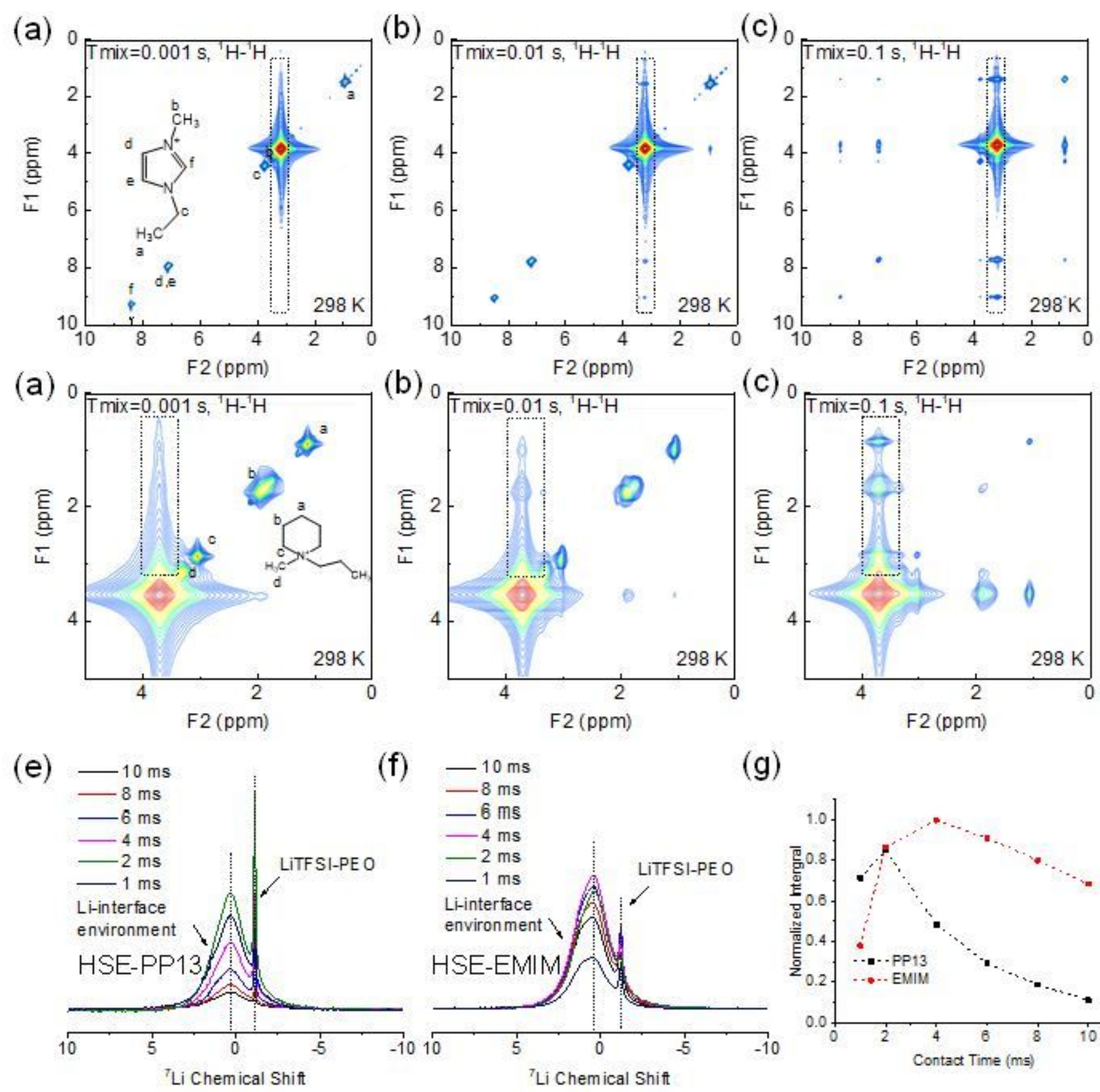

(g)

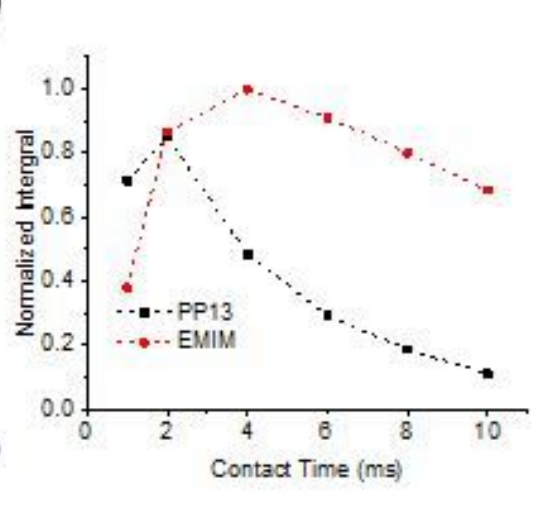

\section{Figure 5}

Locating the position of PP13 TFSI and EMIM TFSI ionic liquids additives in HSE. (a-c) 2D 1H-1H NOESY spectra of the mixture of LiTFSI-PEO- Li6PS5Cl with PP13 TFSI ionic liquid measured at a spinning speed of $5 \mathrm{kHz}$ at $298 \mathrm{~K}$ with Tmix of $0.001,0.01$ and $0.1 \mathrm{~s}$. (e-g) 1D 7Li CPMAS spectra and integral intensity of Li-interface environment (located at 0.26 ppm) in HSE-PP13 and HSE-EMIM with contact times from 1 ms to $10 \mathrm{~ms}$. 
(a)

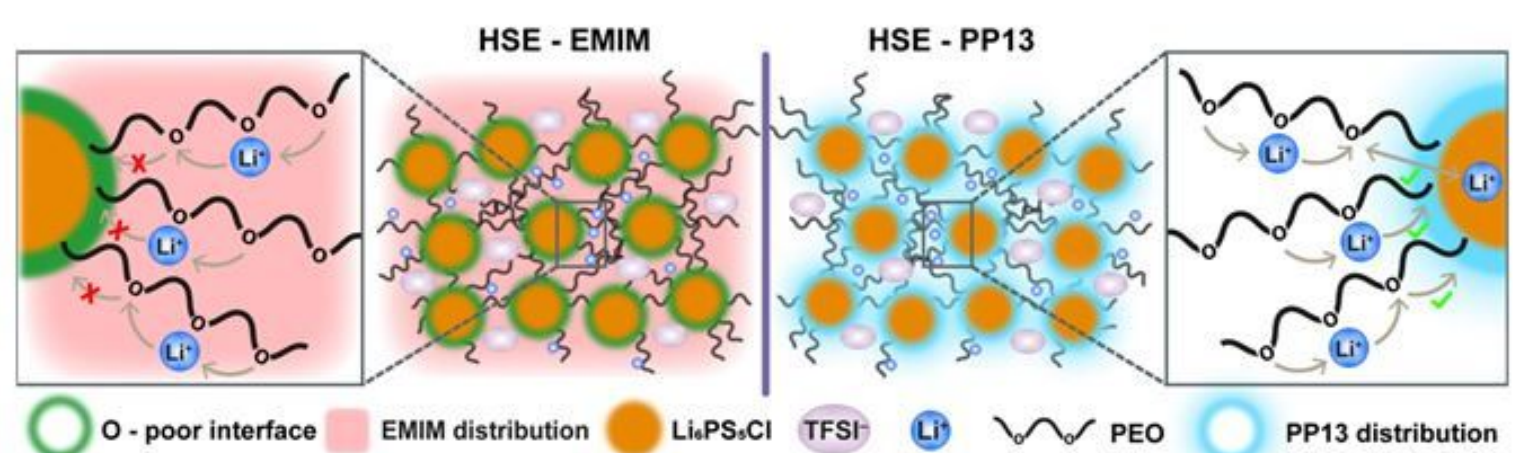

(b)
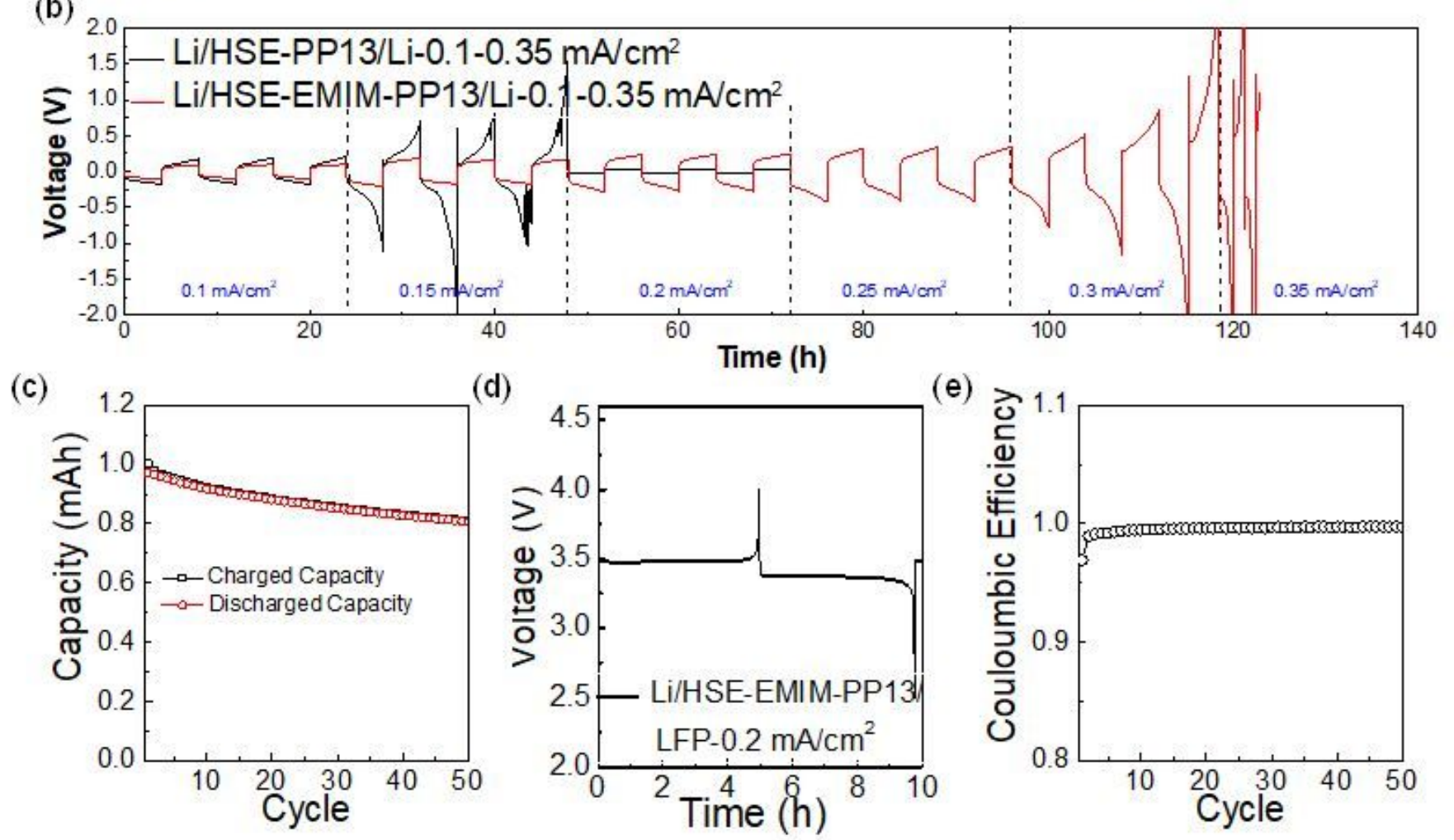

(d)

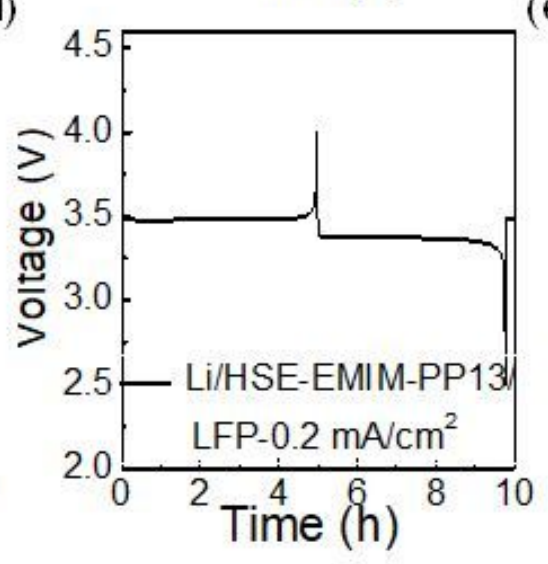

(e)

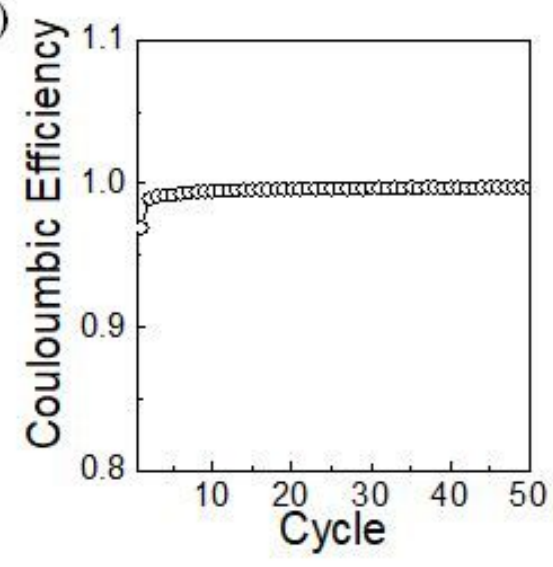

\section{Figure 6}

(a) Proposed Mechanism for Li+ diffusion in HSE with (a) EMIM TFSI and (b) PP13 TFSI ionic liquids additives. (b) Charge and discharge curves of symmetrical battery with LiTFSI-PEO-LPSC HSE with only PP13 TFSI and a mixture of PP13 TFSI and EMIM TFSI ionic liquids. (c-e) (c)Charge and discharge capacity, (d) charge and discharge curve and (d) Coulomb efficiency of LFP/HSE-EMIM-PP13/Li battery cycled at $0.2 \mathrm{~mA} / \mathrm{cm} 2$.

\section{Supplementary Files}

This is a list of supplementary files associated with this preprint. Click to download. 